Original article

\title{
Magnitude of gluconeogenesis and endogenous glucose production: are they predictable in clinical settings?
}

\author{
Isabelle Udin a, b, *, Marc Habisreutinger ${ }^{\mathrm{c}}$, Luc Tappy ${ }^{\mathrm{d}}$, Antoine G. Schneider ${ }^{\mathrm{a}}$, \\ Mette M. Berger ${ }^{a}$ \\ a Service of Adult Intensive Care, Lausanne University Hospital (CHUV), Lausanne, Switzerland \\ ${ }^{\mathrm{b}}$ Anesthesiology Dpt, Lausanne University Hospital (CHUV), Lausanne, Switzerland \\ ${ }^{\mathrm{c}}$ Dpt of Mechanical Engineering, École Polytechnique Fédérale de Lausanne (EPFL), Lausanne, Switzerland \\ d Institute of Physiology, Lausanne University, Lausanne, Switzerland
}

\section{A R T I C L E I N F O}

\section{Article history:}

Received 21 February 2021

Accepted 24 May 2021

\section{Keywords:}

Glucose metabolism

Nutrition

Overfeeding

Underfeeding critically ill

\begin{abstract}
S U M M A R Y
Introduction: Regulation of endogenous glucose production (EGP) is essential for glucose homeostasis. It includes gluconeogenesis (GNG) from non-carbohydrate substrates and hepatic glycogenolysis. Both these pathways are dysregulated in acute stress, but the magnitude of this deregulation cannot be assessed in clinical practice. The study aims at identifying clinically available variables predictive of EGP and GNG magnitude by modeling routinely available data.

Methods: This exploratory study is based on the data from the Supplemental Parenteral Nutrition study 2 (SPN2), which measured EGP and GNG at days 4 and 10 in 23 critically ill patients. The correlation between EGP and GNG and 83 potential clinical indicators were explored, using single-stage and multivariate analysis.

Results: On single-stage analysis, the strongest correlations were noradrenaline dose at day 4 with GNG $(\mathrm{R}=0.71 ; \mathrm{P}=0.0004)$ and Nutrition risk screening score (NRS) with $\mathrm{EGP}(\mathrm{R}=0.42 ; \mathrm{P}=0.05)$. At day 10 , $\mathrm{VO}_{2}(\mathrm{R}=0.59, \mathrm{P}=0.04)$ was correlated with $\mathrm{GNG}$ and $\mathrm{VCO}_{2}$ with $\mathrm{EGP}(\mathrm{R}=0.85, \mathrm{P}=0.00003)$. Cumulated insulin dose between days 5 and 9 was correlated to EGP at day $10(R=0.55, P=0.03)$. Our multivariate model could predict EGP at day $4\left(\mathrm{VCO}_{2}\right.$, glucose and energy intake) with an error coefficient (e.c.) between $7.8 \%$ and $23.4 \%$ (minimal and maximal error), and GNG at day 10 (age, mean and basal blood glucose), with an e.c. of $18.5 \%$ and $29.9 \%$. GNG at day 4 and EGP at day 10 could not be predicted with an e.c. $<40 \%$.

Conclusion: This preliminary exploratory study shows that GNG and EGP have different predictors on days 4 and 10; EGP is more correlated with the metabolic level, while GNG is dependent on external factors. Nevertheless, a bundle of variables could be identified to empirically assess the magnitude of both values. Our results suggest that a robust model might be built, but requires a prospective study including a larger number of patients.
\end{abstract}

๑ 2021 The Authors. Published by Elsevier Ltd. This is an open access article under the CC BY-NC-ND license (http://creativecommons.org/licenses/by-nc-nd/4.0/).

\section{Introduction}

The energy requirements of critically ill patients remain a conundrum and a challenge after four decades of artificial feeding. It still predominantly relies on predictive equations, which have been shown to overestimate patients requirement with potentially deleterious effects [1-3].

\footnotetext{
* Corresponding author. Rue Madeleine 4, CH-1003, Lausanne, Switzerland.

E-mail address: isabelle.udin@chuv.ch (I. Udin).
}

The catabolic responses observed in critically ill patients [4] lead to a dysregulated, enhanced systemic production of endogenous substrates. This energy source is not considered by classical energy balance as assessed by the difference between measured energy expenditure (mEE) and exogenous energy supply. Hence, feeding requirements might be over-evaluated. Indeed, a large indirect calorimetry (IC) study including 1109 patients showed that a mean exogenous energy administration corresponding to 75-90\% of $\mathrm{mEE}$ during the intensive care unit (ICU) stay was associated with the lowest mortality [5]. Further the amount of endogenous substrate 


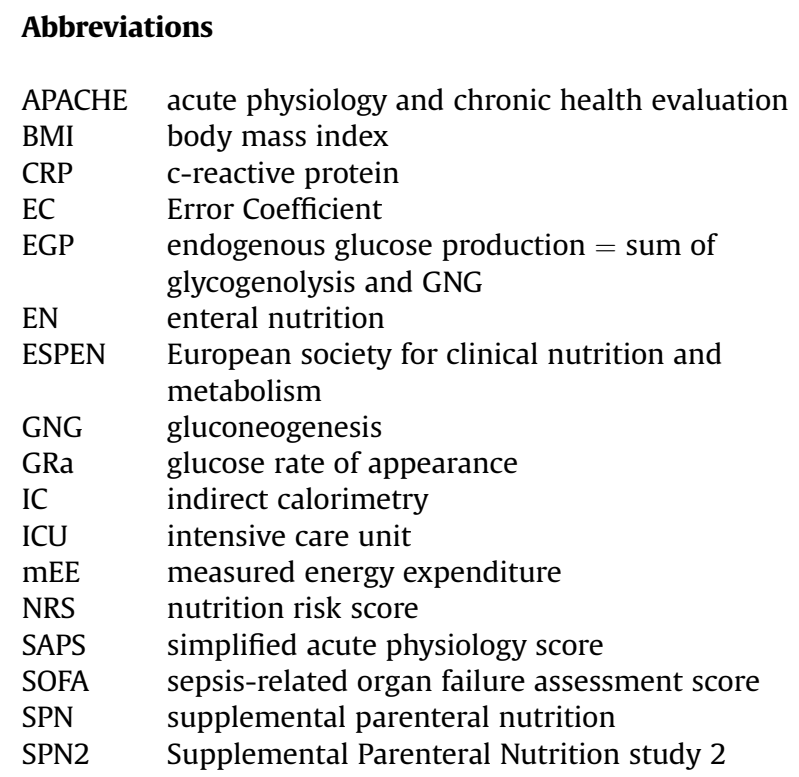

production varies over time in critically ill patients, which changes the exogenous energy required to cover EE.

Blood glucose homeostasis is a priority for the organism. It is achieved by endogenous glucose production (EGP) and exogenous carbohydrate supply (i.e. feeding). EGP relies on glycogenolysis and gluconeogenesis (GNG), the latter taking place in the liver, the kidney, and, to a smaller extent, in the gut.

Current recommendations of the European Society of Clinical Nutrition (ESPEN) are to initiate nutrition therapy within the first $48 \mathrm{~h}$ of admission and to increase it progressively over 3-4 days [7]. During this period, EGP is strongly activated [8]. As demonstrated by tracer studies [9], this activation covers around $2 / 3$ of mEE and appears to last until day 10 [10]. However, the amplitude of EGP is variable between patients $[6,9,10]$.

Full feeding to the target calculated based on predictive equation has been proposed by some authors [11,12] in order to prevent underfeeding. However, in critical illness, contrary to healthy subjects, EGP is not suppressed by feeding or glucose intake after fasting [6]. Hence, overfeeding may occur if endogenous catabolic fluxes are not taken into consideration. This might overwhelm the organism in a situation characterized by major endocrine and inflammatory response, including insulin resistance [12,13]. Hence, the ability to quantify EGP would improve the prediction of extrinsic energy needs, thereby avoiding both under- or over-feeding and their associated complications and mortality [3,14,15]. Isotope tracer methods give reliable estimates, but are expensive, labor intensive and not available in clinical practice $[16,17]$. No practical tool or biomarker enables the evaluation of the magnitude of EGP at the bedside.

The aim of the study was to assess whether a model based on routine clinical variables related to glucose metabolism could predict the magnitude of EGP and GNG, in order to adapt exogenous nutrition delivery on a daily basis. To test this hypothesis, we retrospectively analyzed data from the 23 patients included in the Supplemental parenteral nutrition-2 study (SPN2) [10] for whom GNG and EGP were measured at day 4 and day 10 after initiation of nutritional support. Our working hypothesis was that there were individual or a bundle of clinically available laboratory or clinical variables sufficient to meaningfully adapt exogenous energy administration.

\section{Patients and methods}

The study was a post hoc analysis of the SPN2 trial (NCT02022813), a prospective randomized, controlled trial conducted in 23 critically ill patients, between May 2014 and April 2016.The trial was approved by the Commission Cantonale d'Ethique de la Recherche sur l'Etre Humain (CER-VD 371-13).

\subsection{Patients}

Inclusion criteria were: mechanical ventilation, a functional gut, and, by end of day 3, enteral nutrition (EN) less than $60 \%$ of the energy target determined by equation ( $25 \mathrm{kcal} / \mathrm{kg} / \mathrm{day}$ ). Patients were randomized to either continue receiving $\mathrm{EN}$ alone or to receive EN plus supplemental parenteral nutrition (SPN) to cover $100 \%$ of $\mathrm{mEE}$ from day 4 to day 10 . Protein turnover and glucose kinetics were measured at days 4 and 10 [10] (Fig. 1- appendix).

\subsection{Glucose kinetics}

The complete glucose tracer methods are provided in the appendix. Briefly, tracers were administered on Day 4 and 10 at T0, as a loading dose followed by a continuous infusion. This achieves a near-constant tracer blood level, allowing calculation of the production rate of glucose. The standard formula for the measurement of the rate of glucose appearance in steady state is

\section{$G R a=\frac{\text { tracer infusion rate }}{\text { plasma glucose isotopic enrichment }}$}

GNG was estimated from ${ }^{13} \mathrm{C}$-glucose synthesis during continuous ${ }^{13} \mathrm{C}$-bicarbonate infusion $[10,18]$. The labeled glucose enables measuring the fractional contribution of pyruvate carboxylase to the hepatic oxaloacetate flux, and the hepatic pyruvate dehydrogenase.

\subsection{Indirect calorimetry}

Indirect calorimetry (IC) studies were carried out on Day 4 and 10 during the tracer studies (Quark-RMR, Cosmed, Roma, Italy) lasting $30 \mathrm{~min}$ after stabilization. We used crude values to explore the relationship between $\mathrm{mEE}$ and nutritional intake. Further, we computed "intrinsic feeding" corresponding to the conversion of measured EGP in energy (assuming $1 \mathrm{~g}$ of glucose equals to $4 \mathrm{kcal}$ ) (Fig. 1).

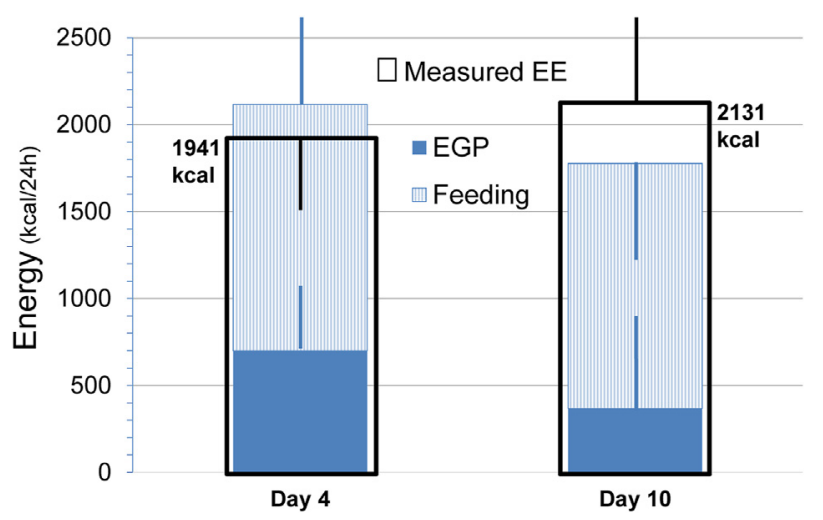

Fig. 1. Mean measured EE compared to the sum of EGP values and extrinsic feeding on Days 4 and 10. 


\subsection{Data extraction and verification}

Data from the SPN2 study were completed with extractions from the computerized patient record (MetaVision ${ }^{\circledR}$, iMDsoft, Tel Aviv, Israel) to provide additional clinically available input data.

\subsection{Model derivation}

\subsubsection{Working definition}

The multivariate and single-stage analysis are based on output and input variables, which are described below.

2.5.1.1. Output variables. The output variables, i.e. those that should be predictable from available clinical variables; EGP and corrected GNG, at day 4 et 10, and the difference (delta) between the 2 respective values.

2.5.1.2. Input variables. Altogether 38 clinical variables and 7 scores and demographic variables were considered at day 4 and 10, and, resulting in 83 variables;

\section{- Demographic variables}

Age, sex, weight, Body Mass Index (BMI).

- Severity scores

Simplified Acute Physiology Score (SAPSII) [19], Acute Physiology And Chronic Health Evaluation (APACHEII) [20], Sepsisrelated Organ Failure Assessment Score (SOFA) [21], Nutrition Risk Screening score (NRS) [22]. All these scores are used on a daily base in the ICU.

\section{- Blood glucose}

In the ICU, blood glucose determinations are generally repeated several times within $24 \mathrm{~h}$. In the present study, additional values are available from the tracer study; A) basal blood glucose, taken before the isotope tracers infusions. B) Average blood glucose of the whole day C) Blood glucose at the beginning of the isotope tracer infusions. D) Average of the last 2 values at the end of the tracer infusion. E) The mean the first and 2 last two blood glucose values during the tracer study. Of note the tracer study includes a glucose infusion which alters the basal glucose values.

\section{- Medications with a direct effect on glucose metabolism}

Insulin ( $\mathrm{UI} / \mathrm{kg} / 24 \mathrm{~h}$ ) needed for a target blood glucose between 6 and $8 \mathrm{mmol} / \mathrm{l}$ (average dose per day, on study day 4, 5, 6, 7, 9, 10), catecholamines (dobutamine, norepinephrine in $\mathrm{mcg} / \mathrm{kg} / 24 \mathrm{~h}$ ), methyprednisolone $(\mathrm{mg} / \mathrm{kg} / 24 \mathrm{~h})$.

\section{- Cortisol level}

The analysis was completed on the frozen sample of the SPN2 study.

\section{- Inflammatory variables}

Leucocyte count, C-reactive protein (CRP: 6am values), patient's temperature (mean of the $6 \mathrm{hr}$ tracer study).

\section{- Nutrition parameters}

Type of nutrition (enteral versus enteral with supplemental parenteral nutrition), energy balance [23], energy target, delivered carbohydrates (g/kg/day), lipids (g/kg/day), and proteins (g/kg/day).

- Calorimetry

$\mathrm{VO}_{2}(\mathrm{~mL} / \mathrm{kg} / \mathrm{min}), \mathrm{VCO}_{2}(\mathrm{~mL} / \mathrm{kg} / \mathrm{min})$, and respiratory quotient.

- Blood gases

$\mathrm{PaCO}_{2}$, lactate.

In a final stage, we assessed the impact of the differences between variables at days 4 and 10 delta values $(\Delta)$.

\section{Single-stage analysis: Correlation coefficients}

First, we assessed the correlation between each input and output variables. In this single-stage analysis, "1" corresponds to a perfect correlation, "-1" to an inverse perfect correlation while 0 means absence of correlation (Table 3 ). We report separately correlations with coefficients $>0.4$ (Table 4 ). We verified the P value (Pearson) with IBM SPSS Statistics ${ }^{\circledR}$.

\section{Multivariate analysis}

Details of the model and its equations are provided in the Appendix. The working method is a multivariate analysis, using a combination of 2,3 and 4 input variables (see definition above) and linking it with one output variable (definition above). The hypothesis was that the model could link input and output variables (Fig. 2 in Appendix). For each of these "links", the error coefficient (e.c.) was calculated, along with the number of samples used, the idea behind being that an e.c. of zero would link perfectly the chosen input variables with an output variable. To calculate e.c., the correlation of the input and output variables were calculated on all samples $\left(\sum\right)$ minus one. The difference between the prediction of all the samples $\left(\sum\right)$ and the excluded one was used to calculate e.c. Each sample was once excluded to calculate one e.c. for each "link".

An uncertainty value was arbitrarily fixed for each variable (see appendix for details). This resulted in two error values for each calculation, corresponding to the plus and minus range (Table 5).

\section{Results}

\subsection{Patients}

The characteristics of the 23 patients of the SPN2 trial are reported in Table 1: there was no difference at baseline between the two original groups EN and SPN. The patients started with similar energy deficit on day 4 with a median (IQR) cumulated energy balance of $-3788(-4428,-3033) \mathrm{kcal}$, with similar median energy intakes day $4(1294(896,-1617)$ kcal). Energy delivery increased in the SPN group by protocol, resulting in significantly different energy balances on day 10 (Table 1 and Appendix Table 2-complement).

\subsection{Glucose kinetics}

As reported in Table 2, EGP decreased over time, while GNG remained stable.

\subsection{Energy fluxes}

The sum of extrinsic (feeding) and intrinsic (EGP + GNG) energy production is close to $\mathrm{mEE}$ (Fig. 1). This results in a $272 \pm 829 \mathrm{kcal} /$ day overfeeding at day 4 , and $-69 \pm 1308 \mathrm{kcal} /$ day at day 10 . 
Table 1

Patients characteristics upon admission, and on days 4 and 10.

\begin{tabular}{|c|c|c|c|c|}
\hline & Units & Day 1 & Day 4 & Day 10 \\
\hline Patients & $\mathrm{N}$ & 23 & & \\
\hline Age & years & $64.13(61.5-72.5)$ & & \\
\hline Gender & $\mathrm{M} / \mathrm{F}$ & $* 19 / 4$ & & \\
\hline Weight & $\mathrm{kg}$ & $\mathbf{8 0 . 4 3}(67-94.5)$ & & \\
\hline Body mass index & $\mathrm{kg} / \mathrm{m} 2$ & $27.25(24.65-30.3)$ & & \\
\hline Ideal body weight & $\mathrm{kg}$ & $66.83(65-71.5)$ & & \\
\hline NRS & points & $4.13(3-5.5)$ & & \\
\hline APACHE II & points & $22.78(18.5-26)$ & & \\
\hline SAPS II & points & $49.87(37.5-59)$ & & \\
\hline SOFA & points & $9.52(7-11)$ & $8.61(6-10)$ & $5.75(3-7.25)$ \\
\hline $\mathrm{mEE}$ & $\mathrm{kcal} / \mathrm{kg} / \mathrm{d}$ & & $24.19(21.2-27.5)$ & $25.52(22.9-28.4)$ \\
\hline Energy Intake & $\mathrm{kcal} / 24 \mathrm{~h}$ & & $1294.4(895.5-1617)$ & $1850.6(1604-2074.5)$ \\
\hline Cumulated Energy balance ${ }^{a}$ in EN group & kcal & & $-3448(-4063-2796)$ & $-6050\left(-10^{\prime} 637-4830\right)$ \\
\hline Cumulated Energy balance $^{a}$ in SPN group & & & $-2741(-3130-2406)$ & $-3416(-4027-2336)$ \\
\hline Basal Blood glucose & $\mathrm{mmol} / \mathrm{L}$ & & $8.13(6.25-9.1)$ & $7.48(6.6-7.9)$ \\
\hline
\end{tabular}

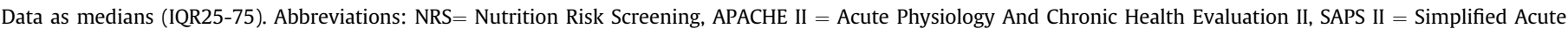
Physiology Score II, SOFA = Sequential Organ Failure Assessment, $\mathrm{mEE}=$ mean energy expenditure.

a Cumulated from admission.

Table 2

The magnitude of EGP and GNG changed over time: EGP was superior to GNG on day 4 , but both values were equivalent on Day 10 .

\begin{tabular}{llll}
\hline & Units & Day 4 & Day 10 \\
\hline EGP & $\mathrm{mg} / \mathrm{kg} / \mathrm{min}$ & $\mathbf{1 . 6 5}(1.19-2.10)$ & $\mathbf{1 . 1 1}(0.54-1.41)$ \\
& $\mathrm{g} / 24 \mathrm{~h}$ & $\mathbf{2 0 8}(\mathbf{1 6 6 . 9}-\mathbf{2 4 0 . 7})$ & $\mathbf{1 4 7 . 8}(87.8-160.1)$ \\
$\mathrm{GNG}$ & $\mathrm{mg} / \mathrm{kg} / \mathrm{min}$ & $\mathbf{1 . 1 2}(0.59-1.35)$ & $\mathbf{1 . 1 1}(0.57-1.64)$ \\
& $\mathrm{g} / 24 \mathrm{~h}$ & $\mathbf{1 2 1 . 9}(\mathbf{7 8 . 1}-\mathbf{1 7 9 . 1})$ & $\mathbf{1 1 2 . 8}(38.9-159.3)$ \\
$\mathrm{mEE}$ & $\mathrm{kcal} / \mathrm{d} / \mathrm{kg}$ & $\mathbf{2 4 . 1 9}(21.24-27.53)$ & $\mathbf{2 5 . 5 2}(22.95-28.45)$ \\
Glucose Intake & $\mathrm{mg} / \mathrm{kg} / \mathrm{min}$ & $\mathbf{1 . 2 0}(0.83-1.72)$ & $\mathbf{2 . 0 6}(1.60-2.24)$ \\
GRa & $\mathrm{mg} / \mathrm{kg} / \mathrm{min}$ & $\mathbf{2 . 9 3}(2.30-3.27)$ & $\mathbf{2 . 8 0}(2.36-3.06)$ \\
Plasma glucose & $\mathrm{mmol} / \mathrm{L}$ & $\mathbf{7 . 6 0}(6.65-8.60)$ & $\mathbf{7 . 4 6}(6.90-8.00)$ \\
Plasma cortisol & $\mathrm{nmol} / \mathrm{L}$ & $\mathbf{6 6 7 . 1 7}(340.5-696.5)$ & $\mathbf{5 2 0 . 4 8}(418.5-651.5)$ \\
\hline
\end{tabular}

Data as means (IQR25-75). Abbreviations: EGP = Endogenous Glucose production, $\mathrm{GNG}=$ Gluconeogenesis, $\mathrm{mEE}=$ mean energy expenditure, $\mathrm{GRa}=$ Glucose rate of appearance.

\subsection{Single-stage analysis: correlation coefficients}

In our first single stage analysis, we found no direct correlation between our input and output variables (Table 3a,b), except for noradrenalin dose and GNG at day $4(\mathrm{R}=0.71 \mathrm{p}<0.0004)$, NRS and EGP at day $4(\mathrm{R}=0.42 ; \mathrm{p}<0.05), \mathrm{VCO}_{2}$ and EGP at day $10(\mathrm{R}=0.85$, $\mathrm{p}<0.00003)$, mean days 5-9 insulin delivery and EGP at day 10 $\left((\mathrm{R}=0.55, \mathrm{p}=0.03)\right.$, and finally $\mathrm{VO}_{2}(\mathrm{R}=0.59, \mathrm{p}=0.04)$ and $\mathrm{VCO}_{2}$ $(\mathrm{R}=0.54 ; \mathrm{p}<0.03)$ with GNG at day 10 .

Table 4 summarizes correlation coefficients $>0.4$ already shown in Table $3 a-b$, with the $\mathrm{p}$ values according to Pearson.

This shows that each output has different indicators, which change over time.

On day 10, EGP is strongly correlated with $\mathrm{VCO}_{2}(\mathrm{R} 0.85$, $\mathrm{P}<0.000$ ), followed by the insulin dose, and respiratory quotient), while it is negatively correlated with blood glucose in the beginning of tracers. GNG is strongly correlated with $\mathrm{VO}_{2}$ and $\mathrm{VCO}_{2}$, to a lesser degree to insulin dose, while it is negatively correlated to noradrenaline and methylprednisolone dose.

\subsection{Multivariate analysis: modelisation}

We collected combinations of up to 4 input variables for each output variable, giving $280^{\prime} 000$ results for each of the 4 output variables. Table 5 presents the results of the models with an error coefficient below $40 \%$. Note that the maximum patient sample is not 23 because all input variables are not always available.

The model could correlate several input to output variables.
EGP on day 4 was best estimated using a combination of VCO2, glucose intake, and energy intake. EGP on day 10 and GNG on day 4 are poorly predictable with this model. GNG on Day 10 is approached by the combination of energy balance and $\mathrm{VO}_{2}$.

\subsection{Evolution between day 4 and 10 , delta values ( 4 ) to predict day 10 outputs}

A complete table of delta value $(\Delta)$ is available in appendix (see Fig. 3).

- Leukocyte count $(\Delta)$ and EGP $(\Delta) ; \mathrm{R}=0.70, \mathrm{P}<0.04$

- RQ $(\Delta)$ and $\operatorname{EGP}(\Delta) ; \mathrm{R}=-0.70, \mathrm{P}<0.05$

- Methylprednisolone $(\Delta)$ and GNG at day $10 ; \mathrm{R}=0.62$ and $\mathrm{P}<0.01$.

\section{Discussion}

In this exploratory analysis, we attempted to identify predictors of EGP and GNG in critically ill patients based on routinely available parameters using single-stage and multivariate analysis. The main findings are that: 1) EGP and GNG on day 4 have different determinants, EGP depending on energy metabolism and GNG on neuroendocrine factors, and 2) that GNG equals EGP on day 10 and is the abnormal component of EGP in these patients as previously shown by our group [24,25]. GNG at day 10 is proportional to $\mathrm{VO}_{2}$, $\mathrm{VCO}_{2}$ and metabolic factors, possibly due to inflammation and $\mathrm{mEE}$ dependent on inflammation as well.

Searching for EGP predictors in diabetes patients, investigations have produced several models. Dala Man et al. [26] proposed a model in which the EGP in the liver is described by two differential equations [27]. The model's inputs were mean insulin, portal insulin and blood glucose concentrations, and the EGP was extrapolated with precision for both normal and type 2 diabetes subjects. More recently, Van Stee et al. described a mathematical procedure to calculate glucose dynamics, based on Dala Man's first equations [27]. Their aim in diabetic patients was to estimate diurnal EGP dynamic directly from plasma glucose, insulin and Insulin Secretory Rate (ISR), gathered from 3 consecutive meals. This method is not applicable in critically ill patients receiving continuous feeding.

The patients included in the present investigation were severe critically patients receiving mechanical ventilation and complex ICU therapies: they were fed using standard techniques (EN, PN or their combination) and enrolled because they encountered the 
Table 3

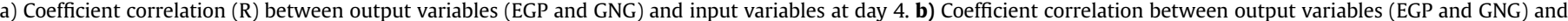

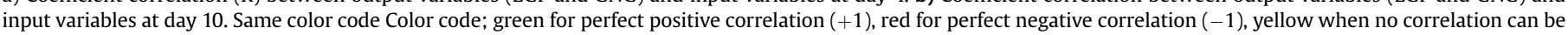
seen $(0)$.

A

\begin{tabular}{|c|c|c|}
\hline & EGP $(\mathrm{mg} / \mathrm{kg} / \mathrm{min})$ & GNG $(\mathrm{mg} / \mathrm{kg} / \mathrm{mn})$ \\
\hline EGP $(\mathrm{mg} / \mathrm{kg} / \mathrm{min})$ & 1.00 & 0.43 \\
\hline GNG corr & 0.43 & 1.00 \\
\hline Blood glucose $\mathrm{mmol} / \mathrm{l}$ & 0.07 & -0.03 \\
\hline Basal BG & 0.11 & -0.08 \\
\hline BG beginning perfusion & 0.24 & -0.23 \\
\hline BG end of perfusion & 0.34 & 0.35 \\
\hline Mean BG during perfusion & 0.36 & 0.06 \\
\hline mEE (CALO) & -0.30 & -0.16 \\
\hline V02 mL/mn/kg & 0.04 & 0.05 \\
\hline VCO2 mL/mn/kg & 0.30 & 0.17 \\
\hline RQ & 0.14 & -0.23 \\
\hline Energy/24H & -0.32 & -0.10 \\
\hline Energy/24h/kg (ideal) & -0.26 & -0.16 \\
\hline Energy balance D3 & 0.10 & -0.09 \\
\hline Energy target reached & 0.10 & 0.11 \\
\hline Glucose $\mathrm{G} / 24 \mathrm{~h}$ & -0.34 & -0.09 \\
\hline Glucose $\mathrm{G} / 24 \mathrm{~h} / \mathrm{kg}$ (ideal) & -0.28 & -0.15 \\
\hline Protein G/24h & -0.17 & -0.06 \\
\hline Protein $\mathrm{G} / 24 \mathrm{~h} / \mathrm{kg}$ (ideal) & -0.13 & -0.12 \\
\hline Lipid G/24H & -0.28 & -0.11 \\
\hline Lipid G/24h/kg (ideal) & -0.25 & -0.17 \\
\hline Age & 0.25 & 0.02 \\
\hline IBW & -0.16 & 0.10 \\
\hline BMI & -0.31 & -0.09 \\
\hline SAPSII & 0.14 & 0.24 \\
\hline SOFA D1 & 0.18 & 0.11 \\
\hline NRS & 0.42 & -0.16 \\
\hline APACHE II & 0.26 & 0.06 \\
\hline Insulin/kg 24h & 0.21 & 0.14 \\
\hline Methylpred/kg 24h & 0.34 & -0.19 \\
\hline Noradrenaline/kg 24h & 0.26 & 0.71 \\
\hline Noradrenaline/kg/J:J0-4 & 0.20 & 0.45 \\
\hline Dobutamine/kg 24h & 0.31 & -0.37 \\
\hline $\mathrm{PaC02}$ & 0.34 & 0.37 \\
\hline Lactate & -0.25 & -0.07 \\
\hline Leukocytes & 0.01 & -0.19 \\
\hline CRP & 0.05 & 0.32 \\
\hline Temperature & -0.31 & -0.12 \\
\hline Cortisol & 0.25 & 0.35 \\
\hline
\end{tabular}

B

\begin{tabular}{|l|c|c}
\hline & EGP $\mathbf{( m g / k g / m i n ) ~}$ GNG $\mathbf{( m g / k g / m n )}$ \\
\hline EGP (mg/kg/min) & 1.00 & 0.06 \\
GNG corr & 0.06 & 1.00 \\
BG mmol/I & -0.21 & -0.33 \\
Basal BG & -0.25 & 0.35 \\
BG beginning perfusion & -0.47 & 0.08 \\
BG end of perfusion & 0.26 & 0.08 \\
BG during perfusion & -0.29 & -0.05 \\
mEE (CALO) & -0.18 & 0.30 \\
V02 mL/mn/kg & -0.15 & 0.58 \\
VCO2 mL/mn/kg & 0.85 & 0.54 \\
RQ & 0.53 & -0.04 \\
Energy/24h & 0.04 & 0.08 \\
Energy/24h/kg (ideal) & 0.12 & -0.08 \\
Energy balance D9 & 0.06 & -0.01 \\
Energy target reached & -0.03 & 0.12 \\
Glucose G/24h & 0.11 & 0.01 \\
Glucose G/24h/kg (ideal) & 0.08 & -0.13 \\
Protein G/24h & -0.23 & 0.03 \\
Protein G/24h/kg (ideal) & 0.00 & -0.14 \\
Lipid G/24h & -0.16 & -0.03 \\
Lipid G/24H/kg (ideal) & -0.08 & -0.11 \\
Age & 0.34 & -0.01 \\
IBW & -0.20 & 0.02 \\
BMI & 0.11 & -0.17 \\
SAPSII & 0.10 & 0.06 \\
SOFA & -0.08 & 0.29 \\
NRS & 0.10 & -0.15 \\
APACHE II & -0.08 & 0.19 \\
Insulin/kg 24H & 0.36 & -0.13 \\
Insulin/kg D5-9 & 0.55 & 0.19 \\
Methylpred/kg24H & -0.17 & -0.42 \\
Nor24H & 0.12 & -0.49 \\
PaCO2 & 0.32 & -0.67 \\
Lactate & -0.20 & -0.13 \\
Leukocytes & -0.19 & 0.03 \\
CRP & 0.24 & 0.22 \\
Temperature & 0.09 & 0.35 \\
Cortisol & -0.08 & 0.05 \\
\hline & & \\
\hline
\end{tabular}

Table 4

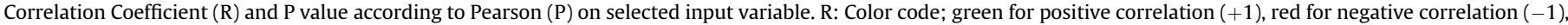

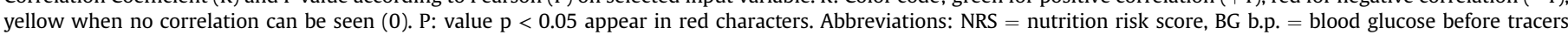
perfusion, $\mathrm{RQ}=$ respiratory quotient, Nor $=$ noradrenaline, Dobu $=$ dobutamine, methylpredn $=$ methyprednisone.

\begin{tabular}{|c|c|c|c|c|c|c|c|c|c|c|c|c|}
\hline & & NRS & BG b.p. & $\begin{array}{c}\mathrm{VO2} \\
\mathrm{mL} / \mathrm{kg} / \mathrm{m}\end{array}$ & $\begin{array}{c}\mathrm{VCO} 2 \\
\mathrm{~mL} / \mathrm{kg} / \mathrm{m}\end{array}$ & RQ & Insuline D5-9 & Nor D4 & Nor D0-4 & Nor D10 & Dobu D4 & $\begin{array}{l}\text { Methylpr } \\
\text { edn D10 }\end{array}$ \\
\hline \multirow[t]{2}{*}{ EGP D4 } & $\mathbf{R}$ & 0.42 & 0.24 & 0.04 & 0.30 & 0.14 & $\mathrm{~N} / \mathrm{A}$ & 0.26 & 0.20 & N/A & 0.31 & $N / A$ \\
\hline & $\mathbf{P}$ & 0.05 & 0.27 & 0.87 & 0.19 & 0.56 & N/A & 0.23 & 0.35 & $\mathrm{~N} / \mathrm{A}$ & 0.15 & $\mathrm{~N} / \mathrm{A}$ \\
\hline \multirow[t]{2}{*}{ GNG D4 } & $R$ & -0.16 & -0.23 & 0.05 & 0.17 & -0.23 & $\mathrm{~N} / \mathrm{A}$ & 0.71 & 0.45 & $\mathrm{~N} / \mathrm{A}$ & -0.37 & $\mathrm{~N} / \mathrm{A}$ \\
\hline & $\mathbf{P}$ & 0.50 & 0.34 & 0.86 & 0.49 & 0.36 & $\mathrm{~N} / \mathrm{A}$ & 0.00 & 0.05 & $\mathrm{~N} / \mathrm{A}$ & 0.11 & $\mathrm{~N} / \mathrm{A}$ \\
\hline \multirow[t]{2}{*}{ EGP D10 } & $\mathbf{R}$ & 0.10 & -0.47 & -0.15 & 0.85 & 0.53 & 0.55 & $\mathrm{~N} / \mathrm{A}$ & $\mathrm{N} / \mathrm{A}$ & 0.12 & $\mathrm{~N} / \mathrm{A}$ & -0.17 \\
\hline & $\mathbf{P}$ & 0.66 & 0.05 & 0.58 & 0.00 & 0.03 & 0.03 & $\mathrm{~N} / \mathrm{A}$ & $\mathrm{N} / \mathrm{A}$ & 0.67 & $\mathrm{~N} / \mathrm{A}$ & 0.52 \\
\hline \multirow[t]{2}{*}{ GNG D10 } & $\mathbf{R}$ & -0.15 & 0.08 & 0.59 & 0.54 & -0.04 & 0.27 & $\mathrm{~N} / \mathrm{A}$ & $\mathrm{N} / \mathrm{A}$ & -0.49 & $\mathrm{~N} / \mathrm{A}$ & -0.42 \\
\hline & $\mathbf{P}$ & 0.54 & 0.78 & 0.04 & 0.03 & 0.89 & 0.27 & $\mathrm{~N} / \mathrm{A}$ & N/A & 0.05 & N/A & 0.11 \\
\hline
\end{tabular}


Table 5

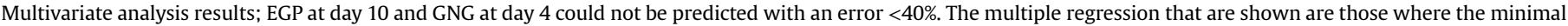
and maximal errors are smallest.

\begin{tabular}{|c|c|c|c|c|c|}
\hline Output & Used samples & Minimal error & Maximal error & Uncertainty & Used input \\
\hline $\mathrm{EGP}(\mathrm{mg} / \mathrm{kg} / \mathrm{mn}) \mathrm{D} 4$ & 15 & 7.8 & 23.4 & 5 & $\begin{array}{l}\text { VCO } 2 \mathrm{~mL} / \mathrm{mn} / \mathrm{kg} \\
\text { Glucose } \mathrm{g} / 24 \mathrm{~h} \\
\text { Energy } \mathrm{kcal} / 24 \mathrm{~h}\end{array}$ \\
\hline $\mathrm{EGP}(\mathrm{mg} / \mathrm{kg} / \mathrm{mn}) \mathrm{D} 4$ & 14 & 9.6 & 22.1 & 5 & $\begin{array}{l}\text { VCO } 2 \mathrm{~mL} / \mathrm{mn} / \mathrm{kg} \\
\text { Glucose } \mathrm{G} / 24 \mathrm{~h} / \mathrm{kg} 1 \mathrm{I} 3 \mathrm{~W} \\
\text { Energy kca } 1 / 24 \mathrm{~h} / \mathrm{kg} 1 \mathrm{BW} \\
\text { Methylprednisone } \mathrm{mg} / \mathrm{kg} / 24 \mathrm{~h}\end{array}$ \\
\hline GNG (mg/kg/mn) D4 & 20 & 35.8 & 45.2 & 5 & $\begin{array}{l}\text { Mean blood glucose } \mathrm{mmol} / \mathrm{L} \\
\text { Basal blood glucose } \mathrm{mmol} / \mathrm{L} \\
\text { Age }\end{array}$ \\
\hline EGP $(\mathrm{mg} / \mathrm{kg} / \mathrm{mn}) \mathrm{D} 10$ & 15 & 45.2 & 49.1 & 5 & $\begin{array}{l}\text { VO2 mL/mn/kg 010-04 } \\
\text { Age } \\
\text { Leukocytes count G/1 }\end{array}$ \\
\hline GNG $(\mathrm{mg} / \mathrm{kg} / \mathrm{mn})$ D10 & 10 & 18.5 & 29.9 & 5 & $\begin{array}{l}\text { V02 mi } / \mathrm{kg} / \mathrm{mn} \\
\text { Energy balance } 010-04\end{array}$ \\
\hline GNG $(\mathrm{mg} / \mathrm{kg} / \mathrm{mn}) \mathrm{D} 10$ & 13 & 28.8 & 37.2 & 5 & $\begin{array}{l}\text { V02 mi } / \mathrm{kg} / \mathrm{mn} \\
\text { Energy } / 24 \mathrm{~h} / \mathrm{kg} 18 \mathrm{~W}\end{array}$ \\
\hline
\end{tabular}

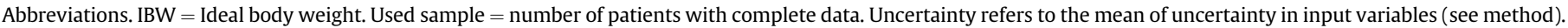

typical enteral feeding challenges. The specificity was that, by study design, due to the use of indirect calorimetry overfeeding was avoided in SPN patients while some degree of underfeeding was present in those on pure EN. The cohort is therefore representative of most ICU patients during the first 10 days after ICU admission. Overfeeding has been shown to occur later in the stay [28]. Fig. 1 shows that some degree of overfeeding occurred on Day 4 due to an elevated EGP and GNG.

Because glucose metabolism is cornerstone to survival, our study focused on glucose and not on proteins or lipids. A constant glucose supply to the brain and other glucose-requiring tissues is dependent on an endogenous glucose production, which is the sum of two biochemical processes, i.e. glycogenolysis and GNG, the latter occurring in the liver, the kidney, and the gut. Blood glucose is often described as the balance between its hepatic production on one hand, and its extra-hepatic use through oxidation and lactate production on the other hand. The real situation is far more complex, since glucose production is autoregulated; a lactate perfusion can stimulate GNG, without raising net glucose production. This is done through an increased glycogen synthesis and a decreased glycogenolysis. In fact, GNG and glyogenolysis determine the hepatic glucose-6-P pool, while the net glucose production is being regulated at the glucokinase/glucose-6-phosphatase cycle. In this regard, glucokinase activity is mainly dependent on (portal) blood glucose level, maintaining it in a relatively narrow range, while glucose-6-phosphatase is regulated by glucagon and other inflammatory mediators. Therefore, the liver plays a central role in blood glucose control by regulating glucose production and glucose/insulin dependent extrahepatic glucose disposal.

The EGP is higher than normal at both days 4 and 10 due to its impaired suppression [24,25]. At day 4, EGP is fueled by both glycogenolysis and gluconeogenesis, with a major contribution of the latter. At day 10, EGP and GNG estimates are similar, indicating that EGP is entirely fueled by GNG. This also implies that GNG is the component of EGP which is abnormal/insulin resistant in these patients.

\subsection{Single-stage analysis}

Most of the clinically available single indicators are noncontributory as predictors. The single-stage analysis shows that EGP is dependent on $\mathrm{VO}_{2}$ and $\mathrm{VCO}_{2}$, i.e. on energy metabolism, while GNG is dependent on pharmacological agents. The EGP at day
4 is correlated to the NRS ( $R=0.42, P<0.05$ ), which is consistent with the fact that nutritional screening catches a metabolic risk $[7,29]$. The NRS score has been shown to be associated with poor outcome when values are $>5$ points [30]. In the present patients, high NRS is correlated to a raised EGP at day 4, indicating a greater deregulation of homeostatic mechanisms. This correlation does not persist at day 10 . Regarding GNG, at day 4 , it is strongly correlated to the total dose of noradrenaline of the last $24 \mathrm{~h}(\mathrm{R}=0.70$, $\mathrm{P}<0.01$ ), while the cumulated dose of the 4 previous days matters less $(\mathrm{R}=0.45, \mathrm{P}<0.05)$.

In addition to having different predictors, EGP and GNG determinants seem to be submitted to a time effect: the associated variables are not the same on Day 4 and day 10 .

At day 10 , EGP is correlated to $\mathrm{VCO}_{2}(\mathrm{R}=0.85$, $\mathrm{P}<0.001)$, respiratory quotient $(R=0.53, P=0.03)$, and doses of insulin perfused on the last four days $(\mathrm{R}=0.55, \mathrm{P}<0.03)$. GNG at day 10 also correlates with $\mathrm{VO}_{2}(\mathrm{R}=0.59, \mathrm{P}<0.04)$ and $\mathrm{VCO}_{2}(\mathrm{R}=0.54, \mathrm{P}<0.03)$, and negatively with doses of norepinephrin and methylprednisolone delivered the same day. In other words, the higher the dose, the lower the GNG.

Critical illness is a stress condition characterized by elevated cortisol values, which it contributes to dysregulation of glucose metabolism [31]. Measured cortisol concentrations presented a wide dispersion on both days, and no correlation with EGP or GNG could be found. One possible explanation is that the hypercortisolemia associated to critical illness is not due to stressinduced activation, but rather to a reduced cortisol metabolism with a diminution of its breakdown, as Boonen and al showed [31]. Consequently, cortisol value cannot be correlated linearly with stress.

In summary, the determinants of GNG and EGP are different; EGP is more related values retrieved by indirect calorimetry i.e. to the metabolic level. GNG seems rather correlated by external factors, like medication (noradrenalin, methylprednisolone).

\subsection{Multivariate analysis}

Multivariate analysis shows that, with a very limited number of subjects, a model based on routinely available clinical variables can predict GNG, with little sensitivity, however. This is nonetheless quite promising since the prediction of GNG may allow prediction of endogenous energy input, and thus improve prescription of exogenous energy intake. 
This approach is purely practical and does not provide useful information of pathophysiological factors. For instance, the fact that EGP on day 10 is correlated with insulin does not mean that insulin is involved in the stimulation of EGP, but instead that high insulin doses identify a subset of patients with dysregulated glucose homeostasis and that such patients are likely to have, through a variety of mechanisms (stress, inflammation, hemodynamic disturbances) a stimulation of EGP.

These predictors may nonetheless be useful in clinical practice, since the objective is not to accurately assess EGP or GNG magnitude nor the pathogenic factors leading to their dysregulation, but merely grossly assessing the degree of impairment of EGP and GNG suppression which should be taken into consideration for nutritional supplies.

\subsection{Limitations and strengths}

The low number of patients is a limitation but is compensated for by the high quality of the metabolic data. Limitation comes from the statistical manipulation of the data and their extrapolations, and the high number of data used. Due to the limited number of patients we could not make a separate analysis of the predictors of EGP between the patients fed enterally or with SPN on Day 10. Further, data mining exposes to false positive results, depending on the power of the model. To avoid this bias, we worked with 22 patients to test the model on the remaining 23rd patient. With this method, we had a prediction reliability between 92.2 and $76.63 \%$ for EGP at day 4 (Table 4). Although promising, it requires testing in higher numbers of patients. The prediction was less reliable at day 10 , also because the input variables were fewer, some of the patients being already discharged from the ICU.

A weakness is an inversion in the relationship between norepinephrine and EGP/GNG; the correlation between GNG and norepinephrine is first positive on Day $4(\mathrm{R}=0.71 ; \mathrm{P}=0.0004)$. The correlation thereafter becomes negative on Day $10(R=-0.49$; $\mathrm{P}=0.05)$. Explanations include a lower number of patients on norepinephrine on day $10(n=21$ patients on day 4 versus $n=5$ on day 10). In addition, the doses were inferior on day 10 . It might also be a statistical coincidence, the correlation being less powerful on day 10.

The originality of the study stands in the use of multivariate analysis based on clinically available data. But not all available input variables could be used in the mathematical model: the correlation coefficient calculation requires a real number, so gender cannot be used in this method. The other constraint is that the mean value cannot be zero (see equation). For this reason, dobutamine at day 10 could not be used for the calculations, being rarely required at this stage.

\section{Conclusion}

The present exploratory multivariate model showed a statistically significant relationship between a set of clinical variables and EGP: although prediction is not highly sensitive at this stage, we propose that the present model be tested in future studies. The bundle of variables differed on days 4 and 10 . No simple predictor could be identified. A larger study is needed to further develop the prediction model and assess its practical implications in terms of individual energy needs.

This initial exploratory study indicates that GNG is the abnormal component of EGP. In the future, the search for EGP predictors could focus on fewer variables $\left(\mathrm{VO}_{2}, \mathrm{VCO}_{2}\right.$, noradrenalin, insulin and NRS score). The design of such a study may be greatly simplified by measuring only EGP on day 10 at relatively low cost.

\section{Author contribution}

IU, LT and MMB conceived the study; IU, MH and MMB extracted the data; MH and MMB did the statistical outwork; IU and MMB generated the figures; IU, LT, AS and MMB generated the first draft of the manuscript; all contributed to critically develop it.

\section{Funding}

The study was realized on internal resource of the Service of Adult Intensive Care Medicine, with no external funding.

\section{Conflicts of interest}

The authors have no conflict of interest to declare related to the present study.

\section{Acknowledgement}

The authors are grateful to Prof. Patrick Thiran (EPFL, Lausanne) for orientation on statistical methods, and to Dr. Christel Tran (Genetic Medicine Unit, Lausanne University Hospital) for critical review of the text.

\section{Appendix A. Supplementary data}

Supplementary data to this article can be found online at https://doi.org/10.1016/j.clnu.2021.05.016.

\section{References}

[1] Cooney RN, Frankenfield DC. Determining energy needs in critically ill patients: equations or indirect calorimeters. Curr Opin Crit Care 2012:18:174-7.

[2] De Waele E, Opsomer T, Honore PM, Diltoer M, Mattens S, Huyghens L, et al. Measured versus calculated resting energy expenditure in critically ill adult patients. Do mathematics match the gold standard? Minerva Anesthesiol 2015;81:272-82.

[3] Zusman O, Theilla M, Cohen J, Kagan I, Bendavid I, Singer P. Resting energy expenditure, calorie and protein consumption in critically ill patients: a retrospective cohort study. Crit Care 2016:20:367.

[4] Moore FA, Phillips SM, McClain CJ, Patel JJ, Martindale RG. Nutrition support for persistent inflammation, immunosuppression, and catabolism syndrome. Nutr Clin Pract : official publication of the American Society for Parenteral and Enteral Nutrition 2017;32. 121S-27S.

[5] Zusman O, Kagan I, Bendavid I, Theilla M, Cohen J, Singer P. Predictive equations versus measured energy expenditure by indirect calorimetry: a retrospective validation. Clin Nutr 2019;38:1206-10.

[6] Wolfe RR. Sepsis as a modulator of adaptation to low and high carbohydrate and low and high fat intakes. Eur J Clin Nutr 1999;53(Suppl 1):S136-42.

[7] Singer P, Reintam-Blaser A, Berger MM, Alhazzani W, Calder PC, Casaer M, et al. ESPEN guidelines: nutrition in the ICU. Clin Nutr 2019;38:48-79.

[8] Oshima T, Berger MM, De Waele E, Guttormsen AB, Heidegger CP, Hiesmayr $\mathrm{M}$, et al. Indirect calorimetry in nutritional therapy. A position paper by the ICALIC study group. Clin Nutr 2017:36:651-62.

[9] Tappy L, Schwarz JM, Schneiter P, Cayeux C, Revelly JP, Fagerquist CK, et al. Effects of isoenergetic glucose-based or lipid-based parenteral nutrition on glucose metabolism, de novo lipogenesis, and respiratory gas exchanges in critically ill patients. Crit Care Med 1998;26:860-7.

[10] Berger MM, Pantet O, Jacquelin-Ravel N, Charriere M, Schmidt S, Becce F, et al. Supplemental parenteral nutrition improves immunity with unchanged carbohydrate and protein metabolism in critically ill patients: the SPN2 randomized tracer study. Clin Nutr 2019;38:2408-16.

[11] Desachy A, Clavel M, Vuagnat A, Normand S, Gissot V, Francois B. Initial efficacy and tolerability of early enteral nutrition with immediate or gradual introduction in intubated patients. Intensive Care Med 2008;34:1054-9.

[12] Casaer MP, Mesotten D, Hermans G, Wouters PJ, Schetz M, Meyfroidt G, et al Early versus late parenteral nutrition in critically ill adults. N Engl J Med 2011;365:506-17.

[13] Revelly JP, Tappy L, Martinez A, Bollmann M, Cayeux MC, Berger MM, et al Lactate and glucose metabolism in severe sepsis and cardiogenic shock. Crit Care Med 2005;33:2235-40.

[14] Dissanaike S, Shelton M, Warner K, O'Keefe GE. The risk for bloodstream infections is associated with increased parenteral caloric intake in patients receiving parenteral nutrition. Crit Care 2007;11:R114. 
[15] Yeh DD, Fuentes E, Quraishi SA, Cropano C, Kaafarani H, Lee J, et al. Adequate nutrition may get you home: effect of caloric/protein deficits on the discharge destination of critically ill surgical patients. J Parenter Enter Nutr 2016;40: 37-44.

[16] Dalla Man C, Caumo A, Basu R, Rizza R, Toffolo G, Cobelli C. Minimal model estimation of glucose absorption and insulin sensitivity from oral test: validation with a tracer method. Am J Physiol Endocrinol Metabol 2004;287: E637-43.

[17] Rizza RA, Toffolo G, Cobelli C. Accurate measurement of postprandial glucose turnover: why is it difficult and how can it Be done (relatively) simply? Diabetes 2016;65:1133-45.

[18] Chung ST, Chacko SK, Sunehag AL, Haymond MW. Measurements of gluconeogenesis and glycogenolysis: a methodological review. Diabetes 2015;64: 3996-4010.

[19] Le Gall JR, Lemeshow S, Saulnier F. A new simplified acute physiology score (SAPS II) based on a European/North American multicenter study. Jama 1994;270:2957-63.

[20] Knaus WA, Draper EA, Wagner DP, Zimmerman JE. Apache II: a severity of disease classification system. Crit Care Med 1985;13:818-29.

[21] Vincent JL, Moreno R, Takala J, Willatts S, DeMedonça A, Bruining H, et al. The SOFA (Sepsis-related Organ Failure Assessment) score to describe organ dysfunction/failure. Intensive Care Med 1996;22:707-10.

[22] Kondrup J, Allison SP, Elia M, Vellas B, Plauth M. Educational and clinical practice committee European society of parenteral and enteral nutrition. ESPEN guidelines for nutrition screening 2002. Clin Nutr 2003;22:415-21.
[23] Plank LD, Hill GL. Energy balance in critical illness. Proc Nutr Soc 2003;62: 545-52.

[24] Chiolero R, Revelly JP, Tappy L. Energy metabolism in sepsis and injury. Nutrition 1997;13:45S-51S.

[25] Tappy L, Cayeux MC, Schneiter P, Schindler C, Temler E, Jéquier E, et al. Effects of lactate on glucose metabolism in healthy subjects and in severely injured hyperglycemic patients. Am J Physiol 1995;268:E630-5.

[26] Dalla Man C, Rizza RA, Cobelli C. Meal simulation model of the glucose-insulin system. IEEE Trans Biomed Eng 2007:54:1740-9.

[27] van Stee MF, Krishnan S, Groen AK, de Graa AA. Determination of physiological parameters for endogenous glucose production in individuals using diurnal data. BMC Biomedical Engineering 2019;1:15. Nov 2019.

[28] Tanaka A, Hamilton K, Eastwood GM, Jones D, Bellomo R. The epidemiology of overfeeding in mechanically ventilated intensive care patients. Clin Nutr ESPEN 2020;36:139-45.

[29] Kondrup J, Rasmussen HH, Hamberg O, Stanga Z. Nutritional risk screening (NRS 2002): a new method based on an analysis of controlled clinical trials. Clin Nutr 2003;22:321-36.

[30] Viana MV, Pantet O, Bagnoud G, Martinez A, Favre E, Charriere M, et al. Metabolic and nutritional characteristics of long-stay critically ill patients. J Clin Med 2019;8:985.

[31] Boonen E, Vervenne H, Meersseman P, Andrew R, Mortier L, Declercq PE, et al. Reduced cortisol metabolism during critical illness. N Engl J Med 2013;368:1477-88. 